\title{
Article
}

\section{E-Textile Metamaterials: Stop Band Pass Filter}

\author{
Bahareh Moradi *(D), Raul Fernández-García and Ignacio Gil Gali (D) \\ Department of Electronic Engineering, Universitat Politècnica de Catalunya, 08222 Terrassa, Barcelona, Spain; \\ raul.fernandez-garcia@upc.edu (R.F.-G.); ignasi.gil@upc.edu (I.G.G.) \\ * Correspondence: bahareh.moradi@upc.edu
}

Citation: Moradi, B.;

Fernández-García, R.; Gali, I.G. E-Textile Metamaterials: Stop Band Pass Filter. Appl. Sci. 2021, 11, 10930. https://doi.org/10.3390/ app112210930

Academic Editor: Shirley Coyle

Received: 8 October 2021

Accepted: 15 November 2021

Published: 19 November 2021

Publisher's Note: MDPI stays neutral with regard to jurisdictional claims in published maps and institutional affiliations.

Copyright: (C) 2021 by the authors. Licensee MDPI, Basel, Switzerland. This article is an open access article distributed under the terms and conditions of the Creative Commons Attribution (CC BY) license (https:// creativecommons.org/licenses/by/ $4.0 /)$.
Abstract: In this paper, the utilization of common fabrics for the manufacturing of e-textile metamaterial is investigated. The proposed design is based on a transmission line loaded with split-ring resonators (SRRs) on a cotton substrate for filter signal application. The proposed design provides a stop band between $2.7 \mathrm{GHz}$ and $4.7 \mathrm{GHz}$, considering a four stage SRR topology. Experimental results showed stop band levels higher than $-30 \mathrm{~dB}$ for the proposed compact embroidered metamaterial e-textiles. The validated results confirmed embroidery as a useful technique to obtain customized electromagnetic filter properties, such as transmitted signal filtering and control, on wearable tech device applications.

Keywords: Electro-textile; Wearable; Electromagnetic; Split-ring resonator; Metamaterial

\section{Introduction}

The merging of electronics and textiles has given rise to new wearable tech devices with new abilities, such as operating at RF/microwave frequencies [1,2]. E-textiles include the conductive yarns that enable electrical conductivity.

On the other hand, metamaterials (MTMs) [3,4] are an attractive topic for researchers recently, which they have applied for improving microwave systems such as antennas, filters, and sensors [5-7]. Recently, MTMs have been integrated into textiles and have led to the development of MTM in a variety of reported fields, such as e-textile metamaterial transmission lines [8], MTM textile sensors [9], MTM microwave absorbers [10], double ring resonators garment antenna [11], and (in the field of filtering) e-textile band pass filters [12]. Furthermore, split-ring resonators (SRRs), which were introduced by [3,13], make an effective magnetic coupling with microstrip topology, that they don't need additional magnetic materials. This coupling allows implementing effective reject band frequency responses and, therefore, it is a convenient compact strategy for implementing stop band filters [14]. This frequency inhibition effect is due to the SRR structure itself, which contains a loop with an identical gap, which can be matched to an equivalent inductance and capacitance, as shown in Figure 1.

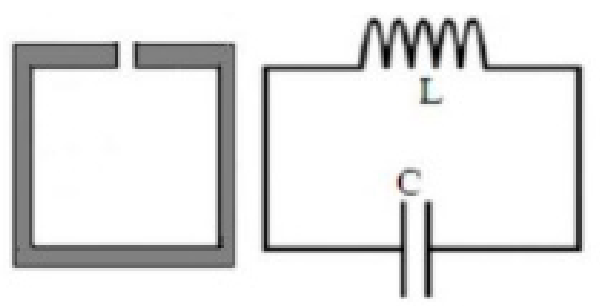

(a)

(b)

Figure 1. Model of SRR (a) and its corresponding circuit model (b).

In this work, usage of fully embroidered MTM microstrip transmission lines, which are coupled to split-ring resonators (SRRs), have been studied by taking into account a cotton 
fabric substrate and considering several levels of stages. The proposed prototypes were designed with CST software, then prototypes were fabricated and measured in bandwidths between 2 and $6 \mathrm{GHz}$. This band covers several of the most important wireless standards and, therefore, are of potential interest for filtering and avoiding signal propagation on certain on-body applications. The paper is structured as follows: in Section 2, the geometric layout and corresponding circuit model of the prototype are presented, simulated, tested, and discussed. Section 3 summarizes the main conclusions of the work.

\section{Metamaterial E-Textile Design, Simulation, and Experimentation}

A microstrip line was designed with a $50 \Omega$ characteristic impedance to allow impedance matching. The substrate of the microstrip line was constructed with cotton, with a dielectric constant $\varepsilon_{\mathrm{r}}=1.9$, thickness $\mathrm{h}=0.43 \mathrm{~mm}$, and loss tangent $\tan \delta=0.053$. In this design, the adhesive copper sheet with constant thickness $\mathrm{t}=35 \mu \mathrm{m}$ was chosen. Figure 2a depicts the prototype model and its dimensions, considering a microstrip width of $\mathrm{W}_{2}=5 \mathrm{~mm}$ and microstrip length of $\mathrm{L}=77 \mathrm{~mm}$.

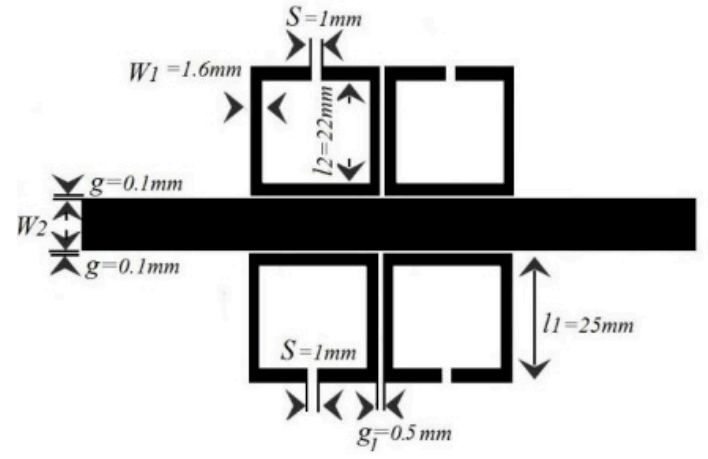

(a)

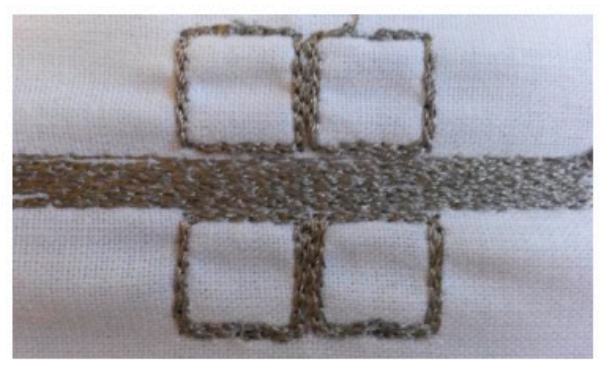

(b)

Figure 2. Geometry of the SRRs coupled with the microstrip line (a). Photograph of the embroidered prototype (b).

The manufactured embroidered e-textile MTM is shown in Figure 2b. Digitizer Ex software was used in order to convert the layout model to a stitch pattern. Then, for the manufacture of the prototype, a SINGER Futura XL-550 embroidery machine was used. The conductor thread that was selected for the stitches on cotton was a commercial Shieldex 117/17 dtex two-ply, for which the features were $99 \%$ pure silver-plated nylon yarn $140 / 17$ dtex with a linear resistance of less than $30 \Omega / \mathrm{cm}[11,12]$.

The prototype was sewn with two types of threads, with consideration of the mechanical limitations of the sewing machine, in which the conductive yarn was selected as bobbin thread and the sulky yarn was used as top thread.

Figure 3 depicts the correspond circuit model of MTM that was loaded with four SRRs. Basically, an SRR behaves as an inductive-capacitive (LC) resonant circuit. In fact, let us consider M1 as the mutual inductance between adjacent rings and M2 as the mutual inductance between the host microstrip line and the SRRs.

By considering the mathematical equations [15], the values equivalent circuit elements are calculated as follows: inductance $L=6.5 \mathrm{nH}$ and capacitance $C=3 \mathrm{pF}$. In addition, $L_{h r}$ corresponds to the intrinsic inductance of the microstrip line. The mutual inductances, $M_{1}$ and $M_{2}$, were calculated as $4.94 \mathrm{nH}$ and $24.2 \mathrm{nH}$, respectively, by using the following equations [16]:

$$
\begin{gathered}
M_{1}=\frac{\mu_{0} L_{1}}{2 \pi}\left[0.4676+\frac{0.059 w_{1}^{2}}{l_{1}^{2}}\right] \\
M_{2}=\frac{\mu_{0} L_{1}}{2 \pi}\left[0.4676+\frac{0.059\left(w_{1}+w_{2}\right)^{2}}{l_{1}^{2}}\right]
\end{gathered}
$$




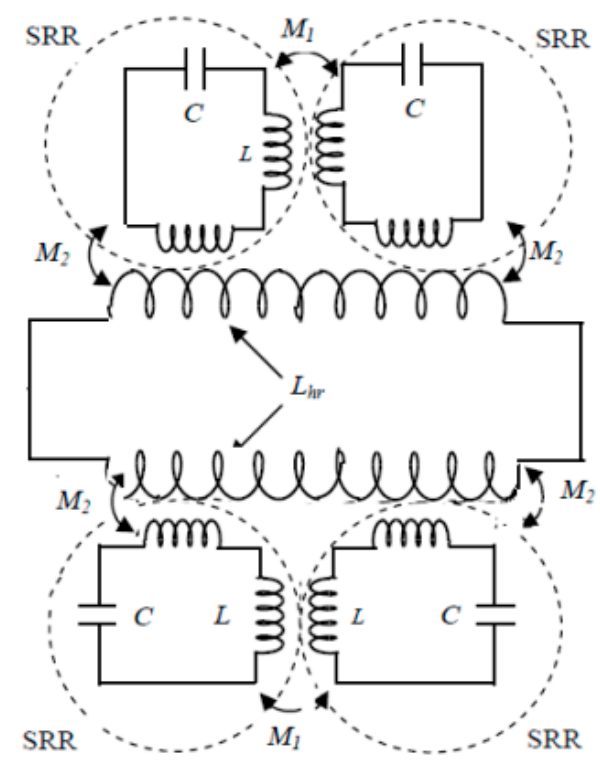

Figure 3. Equivalent circuit model of microstrip line, loaded with four SRRs.

The proposed prototype was embroidered with a $60 \%$ density of satin pattern. The distance between the two needle penetrations in one side of the fabric was proportional to the stitch spacing.

Scattering parameters (S11 and S21) plots of simulation and measurement are illustrated in Figure 4. If a minimum rejection level of $-15 \mathrm{~dB}$ in the stop band is assumed for this filter, the measured stop band extends from 2.7-GHz to $4.7 \mathrm{GHz}$. The simulated and experimental results present a good agreement with minor differences, due to possible mismatching in connectors and fabrication tolerances, with regard to the embroidery process.

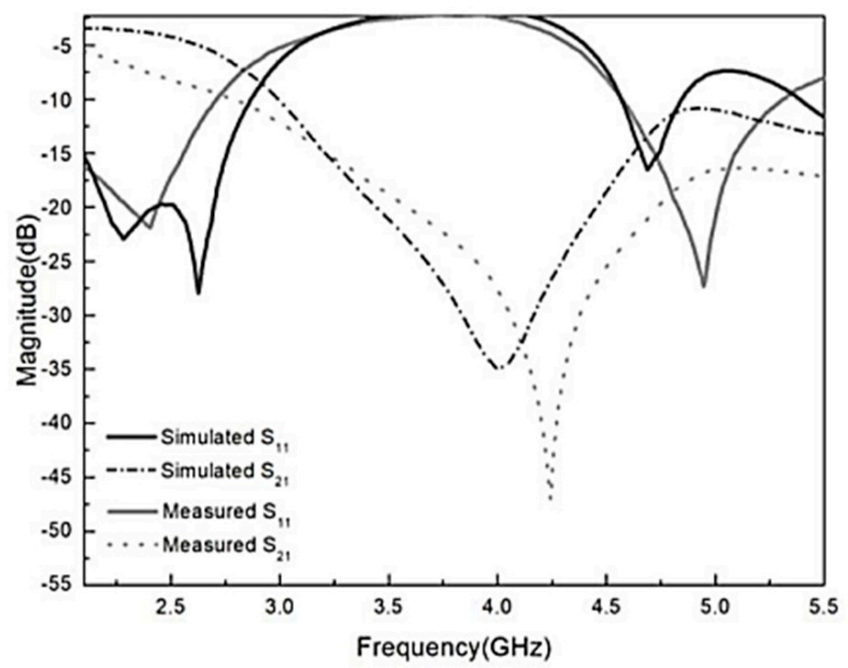

Figure 4. Comparative results between simulation and measurement S-parameter responses of thetransmission line loaded with four SRRs.

The notch bandwidth depends on the coupling of the SRRs and the main signal path implemented and between the top and ground plane. This coupling was mainly controlled by the gap between the microstrip line and SRRs and the thickness of the textile template. In order to prove the performance of the proposed stop band filter, a second filter with two SRRs was proposed, designed, and measured. Figure 5 shows the reflection coefficient response of the transmission line that was loaded with two SRRs. 


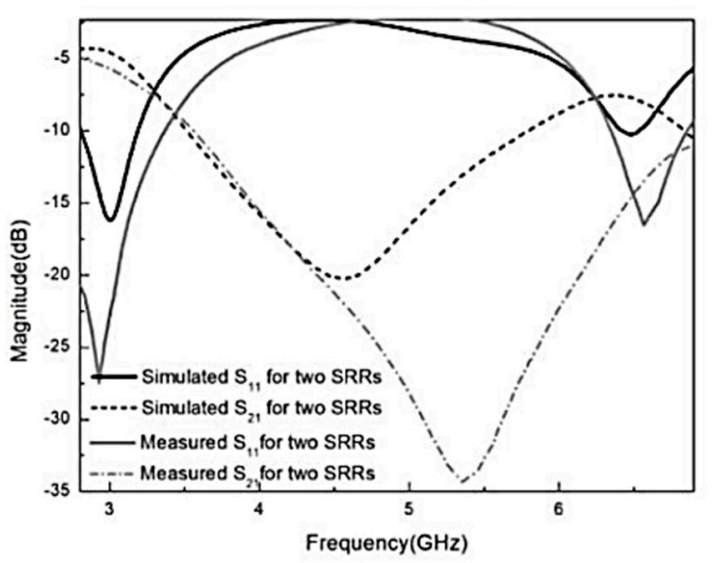

(a)

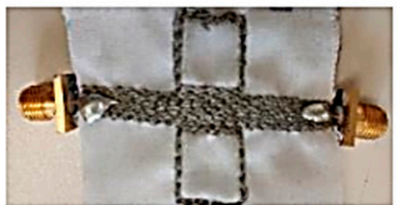

(b)

Figure 5. Reflection coefficient responses of the transmission line loaded with two SRRs (a) and photograph of the embroidered sample (b).

In both cases, a deep rejection band can be observed. Figure 5 shows experimental S-parameter responses of the EM measurement of the embroidered transmission line loaded with two SRRs. The measured proposed design for two SRRs provided a stop band between $3.8 \mathrm{GHz}$ and $6.2 \mathrm{GHz}$ with a $-35 \mathrm{~dB}$ rejection level; whereas, the one with four SRRs provided a stop band between $2.7 \mathrm{GHz}$ and $4.7 \mathrm{GHz}$ with more than $-45 \mathrm{~dB}$. As can be observed, the higher the number of SRR stages, the deeper the level of rejection, exhibiting a well-defined stop bandwidth.

\section{Conclusions}

In this work, the effect of an embroidered textile MTM stop band filter, based on the combination of SRRs and microstrip technology, was simulated and measured. The proposed design was a fully embroidered conductive thread transmission line, loaded with conductive yarn SRRs on a cotton substrate. The experimental measurement results show that the rejection level was significantly high and allowed the effective rejection of undesired microwave signals along an e-textile. Moreover, the proposed design did not affect the signal performance of the allowed frequency range signals over the cotton e-textile.

Author Contributions: Investigation, B.M.; supervision, I.G.G. and R.F.-G.; writing-original draft preparation, B.M.; writing-review and editing, B.M., I.G.G. and R.F.-G. All authors have read and agreed to the published version of the manuscript.

Funding: This work was supported by the Ministry of Economy, Industry and Competitiveness under project TEC2016-79465-R.

Acknowledgments: We are immensely grateful to David Ortiz Perez, Manager of Compliance Business Unit of Idneo Company, for his support.

Conflicts of Interest: The authors declare no conflict of interest.

\section{References}

1. Schneegass, S.; Amft, O. Smart Textiles; Springer: Cham, Switzerland, 2017.

2. Linz, T.; Simon, E.P.; Walter, H. Modeling embroidered contacts for electronics in textiles. J. Text. Inst. 2012, 103, 644-653. [CrossRef]

3. Pendry, J.B.; Holden, A.J.; Robbins, D.J.; Stewart, W.J. Magnetism from conductors and enhanced nonlinear phenomena. IEEE Trans. Microw. Theory Tech. 1999, 47, 2075-2084. [CrossRef]

4. Veselago, V.G. Electrodynamics of substances with simultaneously negative and. Usp. Fiz. Nauk 1967, 92, 517. [CrossRef]

5. Islam, M.M.; Islam, M.T.; Samsuzzaman, M.; Faruque, M.R.I.; Misran, N.; Mansor, M.F. A Miniaturized Antenna with Negative Index Metamaterial Based on Modified SRR and CLS Unit Cell for UWB Microwave Imaging Applications. Materials 2015, 8, 392-407. [CrossRef] [PubMed] 
6. Hinojosa, J.; Saura-Ródenas, A.; Alvarez-Melcon, A.; Martínez-Viviente, F.L. Reconfigurable Coplanar Waveguide (CPW) and Half-Mode Substrate Integrated Waveguide (HMSIW) Band-Stop Filters Using a Varactor-Loaded Metamaterial-Inspired Open Resonator. Materials 2018, 11, 39. [CrossRef] [PubMed]

7. Islam, M.M.; Islam, M.T.; Faruque, M.R.I.; Samsuzzaman, M.; Misran, N.; Arshad, H. Microwave Imaging Sensor Using Compact Metamaterial UWB Antenna with a High Correlation Factor. Materials 2015, 8, 4631-4651. [CrossRef] [PubMed]

8. Moradi, B.; Fernández-García, R.; Gil, I. Effect of smart textile metamaterials on electromagnetic performance for wireless body area network systems. Text. Res. J. 2018. [CrossRef]

9. Tian, X.; Lee, P.M.; Tan, Y.J.; Wu, T.L.; Yao, H.; Zhang, M.; Ho, J.S. Wireless body sensor networks based on metamaterial textiles. Nat. Electron. 2019, 2, 243-251. [CrossRef]

10. Tak, J.; Choi, J. A wearable metamaterial microwave absorber. IEEE Antennas Wirel. Propag. Lett. 2016, 16, 784-787. [CrossRef]

11. Moradi, B.; Martinez, M.; Fernández-García, R.; Gil, I. Wearable ring resonator antenna. Phys. Status Solidi A 2018, 215, 1800410. [CrossRef]

12. Moradi, B.; Fernández-García, R.; Gil, I. Meander microwave band-pass filter on a flexible textile substrate. Electronics $2019,8,11$. [CrossRef]

13. Smith, D.R.; Padilla, W.J.; Vier, D.C.; Nemat-Nasser, S.C.; Schultz, S. Composite medium with simultaneously negative permeability and permittivity. Phys. Rev. Lett. 2000, 84, 4184. [CrossRef] [PubMed]

14. Tu, W.H.; Chang, K. Compact microstrip low-pass filter with sharp rejection. IEEE Microw. Wirel. Compon. Lett. 2005, 15, 404-406.

15. Hong, J.-S.G.; Lancaster, M.J. Microstrip Filters for RF/Microwave Applications; John Wiley \& Sons: Hoboken, NJ, USA, 2001; Volume 64.

16. Joshi, J.G.; Pattnaik, S.S.; Devi, S.; Lohokare, M.R. Bandwidth enhancement and size reduction of microstrip patch antenna by magnetoinductive waveguide loading. Wirel. Eng. Technol. 2011, 2. [CrossRef] 